Article

\title{
A Heuristic Approach to Siting and Design Optimization of an Onshore Wind Farm Layout
}

\author{
Shafiqur Rehman ${ }^{1}{ }^{\mathbb{D}}$, Abdul Baseer Mohammed ${ }^{2, *}$ and Luai Alhems ${ }^{1}$ \\ 1 Center for Engineering Research, Research Institute, King Fahd University of Petroleum and Minerals, \\ Dhahran 31261, Saudi Arabia; srehman@kfupm.edu.sa (S.R.); luaimalh@kfupm.edu.sa (L.A.) \\ 2 Department of Mechanical \& Manufacturing Engineering Technology, Jubail Industrial College, \\ Jubail 31961, Saudi Arabia \\ * Correspondence: baseer_m@jic.edu.sa
}

Received: 4 September 2020; Accepted: 12 November 2020; Published: 14 November 2020

\begin{abstract}
The forecasted electricity demand in Saudi Arabia may be around 120 GW/year by 2032 . As per the latest government announcement, Saudi Arabia is aiming to install $57.5 \mathrm{GW}$ of renewable energy capacity by 2030. In this study, firstly, a wind map is developed based on the historical wind data, recorded over a 39-year period, followed by the development of the geographic information system (GIS)-based multi-criteria decision making (MCDM) model for suitable wind farm site selection for Hijaz, the western region of Saudi Arabia. This region is selected as it has a population density of around 25 per sq. km, the highest in Saudi Arabia. For the model, data from various ecological, environmental, and socioeconomic criteria are considered. Finally, the optimization of the wind farm layout on the identified suitable region of $5.5 \mathrm{~km} \times 4 \mathrm{~km}$ is performed using the deep-array wake model, DAWM. The optimized layout has locations for 30 wind turbines of $3 \mathrm{MW}$ rated capacity. This optimization process minimizes energy losses and costs and maximizes power production. The net and gross energy production from the wind farm are expected to be $143 \mathrm{GWh}$ and 156 GWh, respectively, with an array loss of $8.25 \%$ at a cost of energy of USD 65.66 per MWh, and a capacity factor of $17.7 \%$. The cost calculations include the capital cost of constructing the access roads and a complete collector system with two substations. The optimized turbine positions in the layout have a major and minor axis separation of $1680 \mathrm{~m}$ and $448 \mathrm{~m}$, respectively.
\end{abstract}

Keywords: cost of energy; design optimization of wind farm layout; GIS; site suitability analysis; wake effect; wind power

\section{Introduction}

The amount of energy a country generates is directly related to its overall economy. Energy is consumed by the industrial, residential, transportation, and commercial sectors. It is projected that by 2050, the world energy requirement would experience a two-fold jump [1]. The reasons for exploring various alternative renewable and sustainable resources of energy are the environmental concerns and depletion of fossil fuels caused by their persistent burning [2]. Since the cost of energy generated from the latest commercial wind turbines is at par with traditional energy generated from fossil fuels, wind energy has become one of the most promising renewable, sustainable, and commercially accepted sources of energy [3]. In the year 2019, the new global wind energy installations added are $60.4 \mathrm{GW}$, a 19\% increase from the year 2018, taking the total installations to $651 \mathrm{GW}$ [4]. The forecast for electricity requirements in Saudi Arabia is assumed to be more than $120 \mathrm{GW} /$ year by 2032. As per the latest government directives, Saudi Arabia is planning to install $57.5 \mathrm{GW}$ of renewable capacity in the Kingdom by 2030. The first step in the realization of this goal is the generation of $9.5 \mathrm{GW}$ of energy from renewable sources by 2020 [5]. A 0.4 GW wind farm is under construction in Dumat al-Jandal, 
Al Jawf Province, in the north of Saudi Arabia [6]. However, there are no wind farms planned in other parts of the country. Saudi Arabia has vast vacant land with good wind resource in most regions, which is highly suitable to attain high wind power penetration $[7,8]$.

The first step in planning a wind farm is the accurate determination of the potential location. This location should have a good wind resource and must satisfy all ecological, environmental, and socioeconomic constraints and policies. The multi-criteria decision making (MCDM) analysis in the geographic information system (GIS) background is an ideal tool for finding the suitable location of a wind farm [9]. As one of the earliest studies in wind farm siting, the GIS-based, MCDM analysis was performed in Lancashire, UK, in 2001 [10]. Out of the two approaches adopted, the first approach used the same weightage to all the siting criteria, whereas the second approach used variable weightage based on expert advice [10]. Many similar studies were reported globally after this groundbreaking approach. In Denmark, a tool for MCDM spatial planning was developed for investigating the intricate trade-offs between various options [11]. In Queensland, Australia, three sites, Proserpine, South Johnstone and Hamilton Island, were ranked in order of suitability to build a wind farm. The Weibull parameters were determined by three popular methods. A statistical tool was used to check the accuracy of the results. It was concluded that Hamilton Island the most suitable site for wind farm development [12].

After the identification of the optimum site, the next step in the process is the selection of wind turbines to be installed based on the wind class and requirement of the region followed by the wind farm layout optimization, WFLO. The tight placement of wind turbines causes wind shadowing, known as wake effects [13]. Wake effects reduce the wind power capture efficiency and increase the cost of wind power. Layout optimization models are developed to address this problem [13]. The optimization of wind farm layout, WFL, is done by proper positioning and spacing of wind turbines based on various wake effect models. The PARK model $[14,15]$ is commonly used for WFLO as it is accurate and simple. The PARK model assumes a linear expansion of the wake using momentum conservation, the wind velocity, $V_{x}$ at downstream turbine wake, which is given by:

$$
V_{x}=V_{0}\left(1-2 a\left(\frac{r_{0}}{r_{0}+\propto x}\right)^{2}\right)
$$

where $V_{0}$ is the initial wind velocity at an upstream wind turbine, $r_{0}$ is downstream turbine rotor radius, $\alpha$ is the wake spreading coefficient, $x$ is the turbine spacing, and a is axial induction, the relative decrease in wind speed, which can be represented by:

$$
a=\frac{V_{o}-u}{V_{o}}
$$

where $u$ is the unhindered wind velocity. According to the actuator disk theory, the single wind turbine power efficiency $C_{P}$ and the thrust efficiency $C_{T}$ are:

$$
\begin{gathered}
C_{P}=\frac{P_{\text {turbine }}}{P_{\text {wind }}}=4 a(1-a)^{2} \\
C_{T}=\frac{\text { Thrust Force }}{\text { Dynamic Force }}=4 a(1-a)
\end{gathered}
$$

In another similar study, an innovative approach was proposed for onshore WFLO based on the characteristics of wind turbines. Studies of different combinations of commercially available wind turbines generated more than twenty thousand layout options. Jensen's model was used for optimization, which is a modified PARK model. It was observed that both reducing the number of wind turbines and minimizing the rated power capacities maximize energy production, whereas using different rated power turbines at different hub heights is not a very effective approach [16]. 
Tifroute and Bouzahir developed a mathematical optimization scheme for WFLO using a modified Jensen's model. The wake loss was calculated and expressed with total power output as a differentiable function in terms of the locations of the wind turbines [17]. Charhouni et al. developed a model for the optimization of large wind farms [18]. A genetic algorithm with continuous layout representation was developed. This study aimed to analyze the effect of wind turbine types on wind farm efficiency; for this reason, four different commercial wind turbines were selected. The results showed that designing a wind farm with wind turbines with high rated power gives the best design layout.

The PARK model is not very efficient in estimating the wake losses in large capacity wind farms with several wind turbines in rows. The optimization for the wake loss can be achieved efficiently only through erudite numerical modeling. The deep-array wake model, DAWM, developed by AWS Truepower and implemented in the Openwind plant design and optimization program is most suitable to address this task. The model was first proposed by Sten Frandsen [19] in which an area of high uniform surface roughness was considered with an infinite array of wind turbines. The windfarm equivalent roughness $Z_{00}$ is given by:

$$
Z_{00}=h_{H} \exp \left(\frac{k}{\sqrt{c_{t}+\left(k / \ln \left(h_{H} / Z_{0}\right)\right)^{2}}}\right)
$$

In this equation, $h_{H}$ is the hub height, $k$ is the von Karman constant, usually considered $0.4, Z_{0}$ is the ambient roughness between turbines, and $c_{t}$ is the distributed thrust coefficient given by:

$$
c_{t}=\frac{\pi}{8 S_{d} S_{c}} C_{T}
$$

where $C_{T}$ is the turbine thrust coefficient and $S_{d}$ and $S_{c}$ are the mean downwind and crosswind spacing. According to this theory, the ambient roughness does not affect the wake loss as much as the spacing between turbines.

Some of the state-of-the-art wind farm optimization approaches include a new bi-criteria identification and relocation mechanism to different versions of genetic algorithms, conventional and proposed. The effectiveness of this new approach is tested by conducting experiments in two case studies; the results show improvement over the conventional Gaussian wake model, the overall efficiency increased by around 7\% [20]. Ju and Liu emphasized that there may be a higher chance of getting a suboptimal wind farm layout when adopting the Conventional Genetic Algorithm approach. To address the limitations, they proposed novel algorithms with the self-adaptivity capability of individuals, which is an essential step observed in the natural world, called the Adaptive Genetic Algorithm and Self-Informed Genetic Algorithm. There were some improvements in terms of overall efficiency and the time needed to reach an optimal layout [21]. A novel three-dimensional Gaussian wake model is developed and adopted for the optimization of a wind farm layout. The results are validated by wind tunnel measured data and compared with the one-dimensional and the two-dimensional wake models. This new model was found to be more accurate for non-uniform wind farm layout compared to one and two-dimensional Gaussian models and Jensen's model [22].

Even after numerous studies, deciphering and optimizing the wake loss in a wind farm is a sizeable task. Wake effect in the downstream turbines due to the hindrances caused by the upstream turbines can affect its efficiency by almost $20 \%[23,24]$. This reduction in efficiency can be as high as $70 \%$ if the wind turbines are perfectly aligned to the direction of the wind, for wind speeds lower than the rated wind speed of the turbines, and tightly spaced layouts. In this study, firstly, the energy requirement of the five areas of Saudi Arabia is studied by comparing their population density. Then for the area with the highest population density, the Hijaz region, a complete set of ecological, environmental, and socioeconomic constraints and policies are identified without reservations, and data are procured for GIS-based MCDM for wind farm site suitability analysis performed in ArcMap. 
The long-term wind speed data for almost 40 years are obtained from nine various stations of the Hijaz region. The detailed wind resource assessment is performed in Windographer software $[25,26]$. A spatial interpolation method, inverse distance weighted, IDW, is used to develop an accurate wind map for the region. All the identified criteria are given equal weightage in the multi-criteria model, therefore, even if a single criterion condition fails, the complete accompanying area is considered unsuitable. The design optimization of the wind farm layout is performed followed by the calculations of production of wind energy and the cost of energy in OpenWind software developed by AWS Truepower. The cost of energy calculations also includes the capital cost required to build access roads and the collector system with two substations.

This study will help to realize the initial goal of producing 9.5 GW of energy from renewables by the end of 2023 and will also help in partially achieving the target of producing 57.5 GW by 2030 . The novelty of this study is the heuristic approach adopted which includes the combination of site selection based on GIS-based MCDM analysis involving all the criteria which directly or indirectly affect the wind farm siting and optimization of the onshore wind farms on the selected site using the DAWM wake effect model. In all the wind farm design and optimization studies, the GIS-based siting methodology of the wind farm is ignored.

\section{Description of the Study Area}

Saudi Arabia consists of five geographical areas Najd (Center), Hijaz (West), northern, southern, and eastern area. In 1991, these five areas were divided into thirteen administrative provinces as shown in Table 1 and Figure 1, each with separate governorates [24]. In this study, the region of Hijaz, the western region that consists of three provinces, Tabuk, Al-Madinah Al-Monawarah, and Makkah Al-Mokarramah, as shown in Figure 1, is selected for siting of the wind farm and design optimization of that layout. This region is selected as it has the highest population of 11.3 million and the highest population density of 25 per $\mathrm{km}^{2}$ among all the areas as shown in Table 1 [25]. All three provinces are located on the red seashore, which can be a huge advantage when importing the wind turbine parts via sea route.

Table 1. The demographics of five areas of Saudi Arabia.

\begin{tabular}{|c|c|c|c|c|}
\hline Areas & Province & $\begin{array}{c}\text { Population, } \\
2016\end{array}$ & $\begin{array}{c}\text { Area } \\
\left(\mathrm{km}^{2}\right)\end{array}$ & $\begin{array}{l}\text { Population Density, } \\
\text { per } \mathbf{k m}^{2}\end{array}$ \\
\hline \multirow{2}{*}{ Najd (Central) area } & Al-Qaseem & $1,387,996$ & 58,046 & \multirow{2}{*}{20.31} \\
\hline & Al-Riyadh & $8,002,100$ & 404,240 & \\
\hline \multirow{3}{*}{ Hijaz (western) area } & Tabuk & 890,922 & 146,072 & \multirow{3}{*}{25.04} \\
\hline & Al-Madinah Al-Monawarah & $2,080,436$ & 151,900 & \\
\hline & Makkah Al-Mokarramah & $8,325,304$ & 153,128 & \\
\hline \multirow{3}{*}{ Northern area } & Northern Borders & 359,235 & 111,797 & \multirow{3}{*}{4.88} \\
\hline & Al-Jouf & 497,509 & 100,212 & \\
\hline & Hail & 684,619 & 103,887 & \\
\hline \multirow{4}{*}{ Southern area } & Al-Baha & 466,384 & 9921 & \multirow{4}{*}{19.10} \\
\hline & Jazan & $1,533,680$ & 11,671 & \\
\hline & Aseer & $2,164,172$ & 76,693 & \\
\hline & Najran & 569,332 & 149,511 & \\
\hline Eastern area & Eastern Province & $4,780,619$ & 672,522 & 7.11 \\
\hline
\end{tabular}




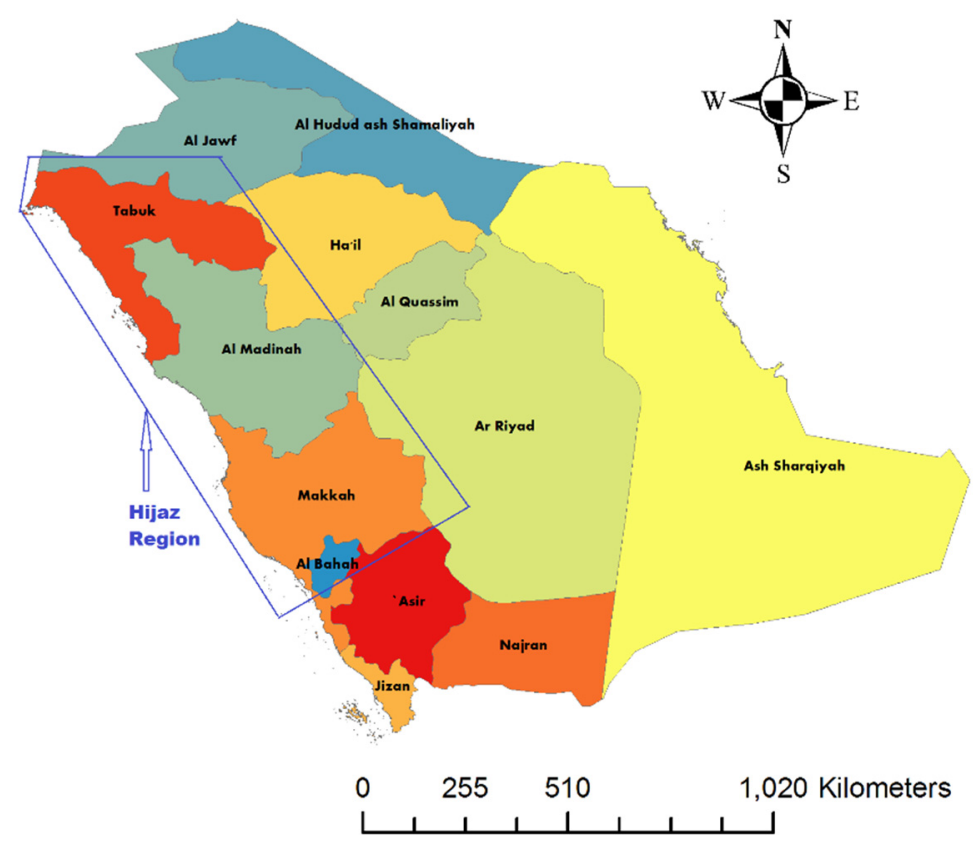

Figure 1. The provinces of Saudi Arabia.

\section{Wind Farm Site Selection in Hijaz Region}

In this study, firstly, a comprehensive set of ecological, environmental, and socioeconomic constraints and policies for GIS-based MCDM is identified for wind farm site suitability analysis in the Hijaz region, west of Saudi Arabia. All the criteria are given the same weightage in this MCDM model, therefore, even if a single criterion condition fails, the complete accompanying area is considered unsuitable. Then, on the identified suitable region, the design optimization of the wind farm layout is performed using the deep-array wake model, DAWM. Finally, a comprehensive economic analysis is performed with expected wind energy production from the wind farm. The detailed, step-by-step approach is explained below.

\subsection{Wind Farm Site Selection Criteria}

All the criteria that may affect site selection were judiciously identified from the literature. The wind speed is a vital criterion in all similar studies [26-28]. In this study, the historical hourly time step wind speed data of nearly 40 years were obtained for nine stations throughout the Hijaz region [29]. The location of these nine stations is depicted on the map shown in Figure 2. The mean wind speed at $50 \mathrm{~m}$ AGL (above ground level), the altitude and location of the stations are presented in Table 2.

Table 2. The location (latitude and longitude) and altitude of stations with mean wind speed.

\begin{tabular}{cccccc}
\hline S.No & Wind Station & $\begin{array}{c}\text { Latitude } \\
(\mathbf{N})\end{array}$ & $\begin{array}{c}\text { Longitude } \\
\mathbf{( E )}\end{array}$ & $\begin{array}{c}\text { Altitude } \\
\mathbf{( m )}\end{array}$ & $\begin{array}{c}\text { Av. Wind Speed at 50 m AGL } \\
(\mathbf{m} / \mathbf{s})\end{array}$ \\
\hline 1 & Al Baha & 20 & 41.25 & 1652 & 4 \\
2 & Al Lith & 20 & 40.625 & - & 3.67 \\
3 & Jeddah & 21.5 & 39.375 & 17 & 5.24 \\
4 & Madinah & 24.5 & 39.75 & 636 & 5.55 \\
5 & Makkah & 21.5 & 40 & 240 & 4.99 \\
6 & Tabuk & 28.5 & 36.875 & 768 & 5.45 \\
7 & Ummluj & 25 & 37.5 & 411 & 5.22 \\
8 & Wejh & 26.5 & 36.25 & 24 & 5.99 \\
9 & Yanbo & 24 & 38.125 & 10 & 5.08 \\
\hline
\end{tabular}




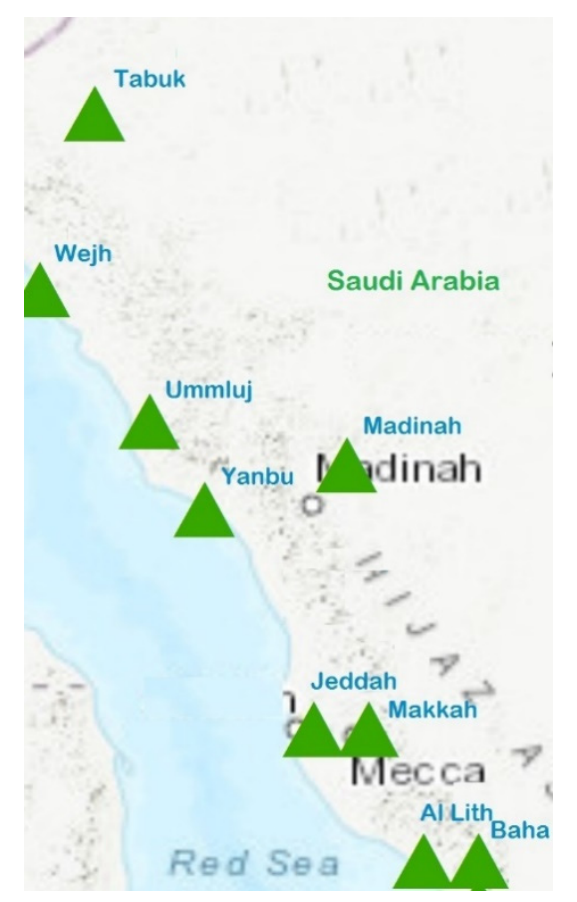

Figure 2. The wind stations in the Hijaz region.

The wind speed data at the weather stations are recorded at $10 \mathrm{~m}$ AGL and interpolated to $50 \mathrm{~m}$ AGL by using Hellmann's power law, also generally known as the one-seventh power law [27].

$$
V_{2}=V_{1}\left(\frac{Z_{2}}{Z_{1}}\right)^{n}
$$

where $V_{1}$ and $V_{2}$ are the mean wind speeds at height $Z_{1}$ and $Z_{2}$, and $n$ is the wind shear coefficient, dependent on the site terrain. This value is assumed to be $1 / 7$ for open flat land with few trees [28,29].

The proximity of a prospective wind farm to the electricity grid is important to avoid transmission inefficiencies and costs. For this study, the national electrical grid (Figure 3) and power station map was procured from the annual report published by the Saudi Electrical Company [30].

A wind farm is planned away from residential areas to avoid noise and also for ecological reasons. However, this distance should not be too far from the immediate residential community for optimum supply power [31]. This distance range is not consistent in all studies and mainly depends on the local policies $[28,32,33]$. A wind farm site needs a nearby road to transport wind turbine parts for installation and future maintenance work. A road for vehicles that carry wind turbine parts (blades, tower, and nacelle) to the installation locations needs to be built from the existing highways. All the studies considered this criterion of distances from the existing road, however, there is a huge variation from $5000 \mathrm{~m}$ in some studies to $100 \mathrm{~m}$ in a few others [10,32,34,35]. The GIS shapefiles of roads (Figure 4) are downloaded from Stanford University's online library [36].

A wind farm should be located at a safe distance away from the airports (Figure 4) to avoid interference of wind turbines with the communication radar signal generated from aircraft. A safe distance of 3000 to $6000 \mathrm{~m}$ around airports is found to be used in the literature [31,32].

A suitable distance of a wind farm from protected areas such as parks, forests, and places of tourism is essential for aesthetic reasons $[10,31,32,34]$. Birds may collide with the wind turbine rotors, so a wind farm should be away from the migrating path of the birds and important bird areas, IBA [31,34]. Birds migrate to Europe from Asia and Africa and return with Saudi Arabia as a transit point [37]. The Arabian peninsula is home to fifteen IBAs [38], but none are located completely inside the Saudi boundary due to scarcity of water bodies, and natural habitats for survival. The criteria of unsuitable distance from water bodies and waterways are important for ecological reasons [10,31,32]. Saudi Arabia 
is very scarce in perennial rivers but there are a few springs, water bodies, and non-perennial rivers as shown in Figure 4.

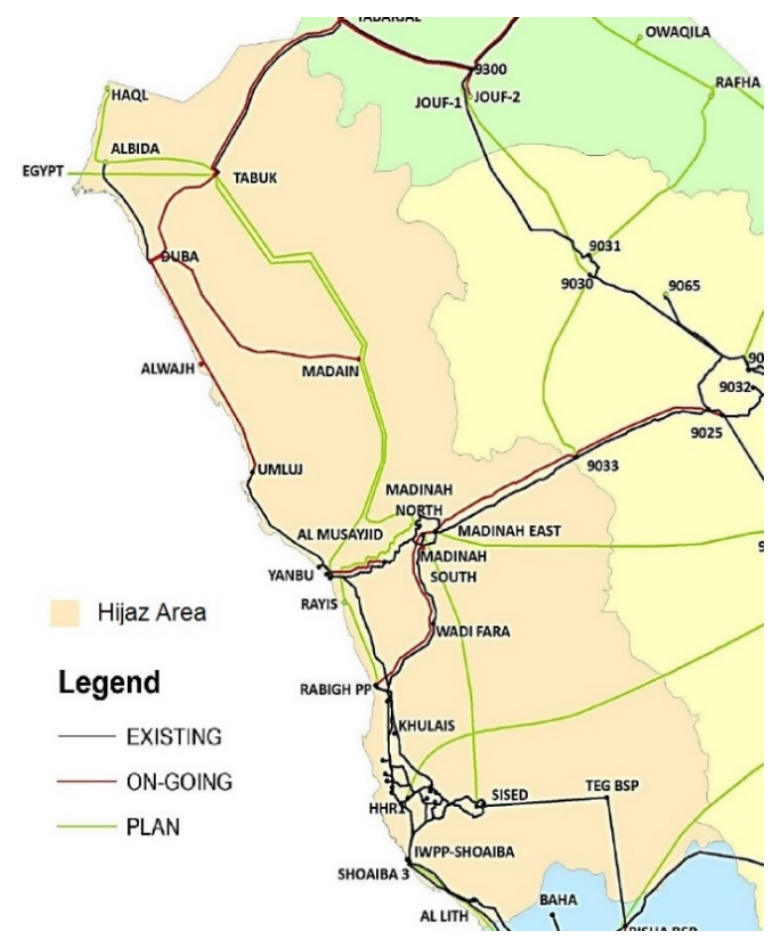

Figure 3. The electricity grid of the Hijaz region (Saudi Electricity Company, 2018).

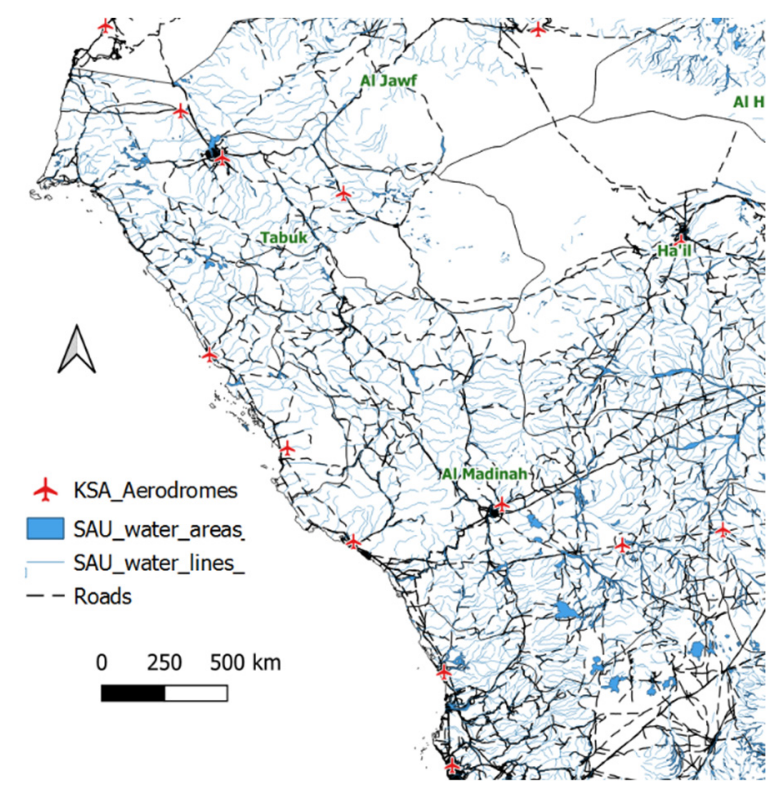

Figure 4. The roads, airports, and water bodies.

The wind farm site and the adjacent area should be reasonably plain to provide easy access for installation followed by maintenance of wind turbines. Furthermore, the wind flow will be hampered in areas with high terrain slope. The acceptable maximum slope is considered between $10 \%$ [10] to $30 \%$ [39]. Some studies completely neglected the criteria of slope $[11,31,40]$. The areas with slope more than $15 \%$ in the Hijaz region are shown in Figure 5. 


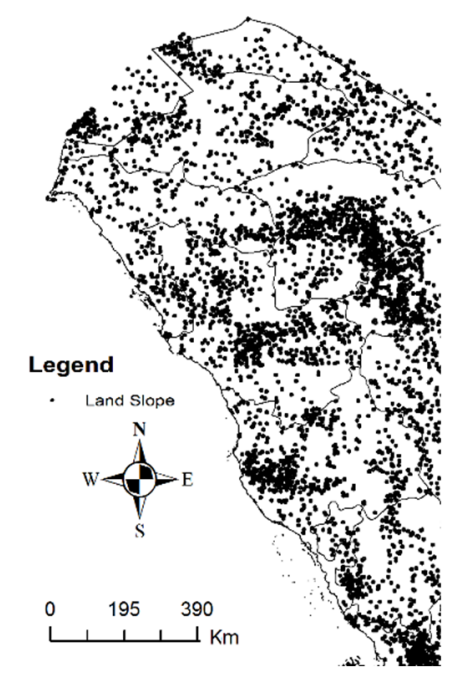

Figure 5. The areas with slope greater than $15 \%$.

\subsection{Multicriteria Decision Making}

All the criteria are assessed concurrently in MCDM analysis using ESRI's ArcMap 10.7, 2019. MCDM is an approach to make complex decisions based on the assessment of several input criteria [34]. Map layers, each representing suitable criteria, are overlaid over each other to develop a final site suitability map. The identified criteria with the restrictions are presented in Figure 6. Table 3 summarizes the categories of identified criteria with restrictions on each. After the application of these restrictions, the final suitability map is generated, as shown in the conceptual model (Figure 6).

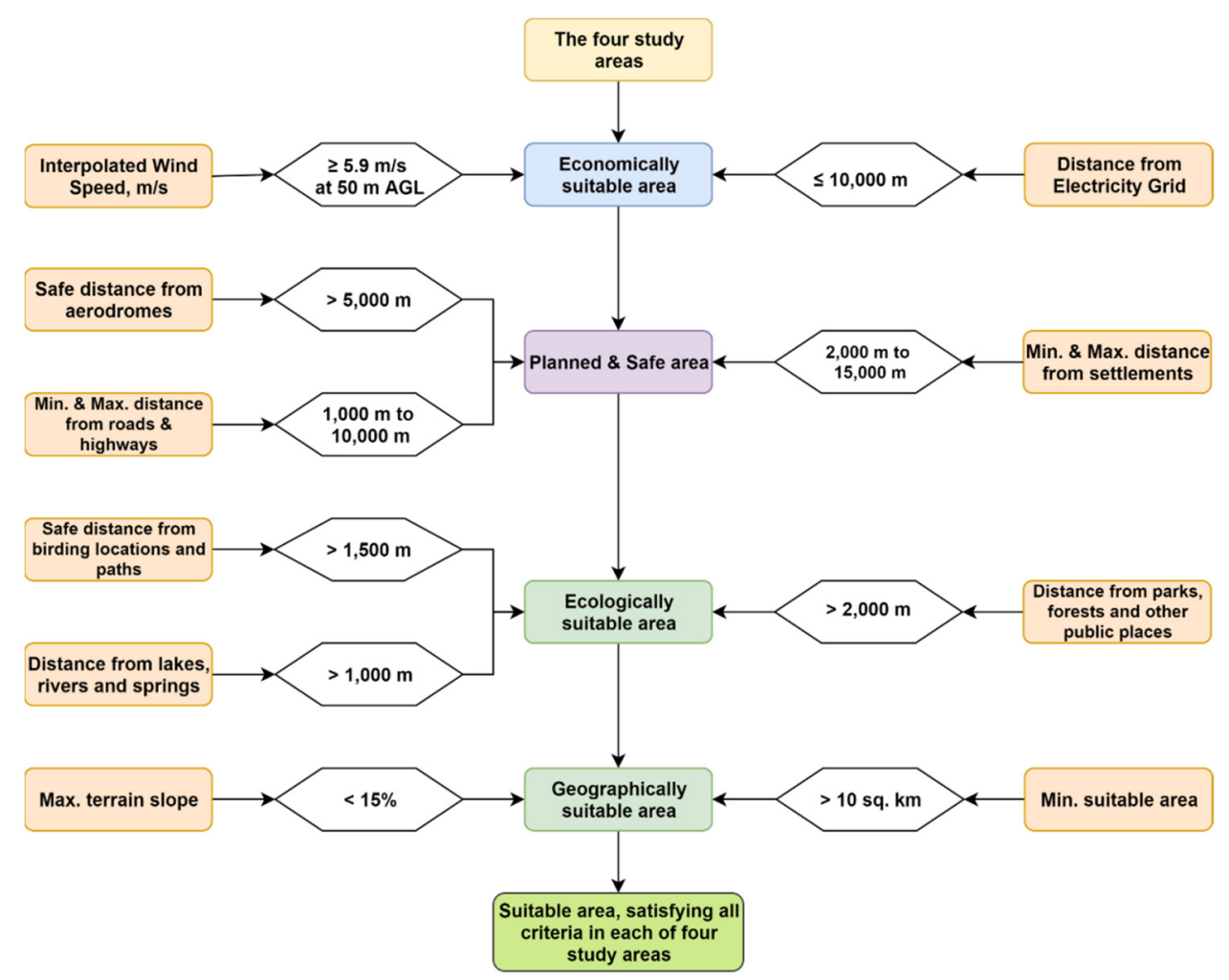

Figure 6. The conceptual model of the site suitability analysis. 
Table 3. Criteria categories with restrictions.

\begin{tabular}{ccc}
\hline Category & Criteria & Restriction \\
\hline \multirow{2}{*}{ Economic } & High mean wind speed & $>5.8 \mathrm{~m} / \mathrm{s}$ \\
& Proximity to the national electricity grid & $<10,000 \mathrm{~m}$ \\
\hline Safety & Safe distance from airports & $>5000 \mathrm{~m}$ \\
\hline \multirow{2}{*}{ Planning } & Distance from roads & 1000 to $10,000 \mathrm{~m}$ \\
& Distance from settlements & 2000 to $15,000 \mathrm{~m}$ \\
\hline \multirow{2}{*}{ Ecologic } & Safe distance from flying paths of birds & $>1500 \mathrm{~m}$ \\
& Distance from lakes, rivers, and springs & $>1000 \mathrm{~m}$ \\
\multirow{2}{*}{ Geographic } & Distance from public places, parks, and forests & $>2000 \mathrm{~m}$ \\
\hline
\end{tabular}

\subsection{The Wind Map of Hijaz Area}

The spatial analysis of wind speed is performed using the inverse distance weighted, IDW, using a linear weighted combination of the available data points. To develop the wind map, the raster wind data are reclassified into nine classes as shown in Figure 7. This raster wind data at $50 \mathrm{~m}$ AGL are found to be between 3.7 to $6.4 \mathrm{~m} / \mathrm{s}$. In this study, the two best classes, 5.8 to $6.4 \mathrm{~m} / \mathrm{s}$ are considered suitable for wind farm development. It can be observed that excellent wind resources exist near the $\mathrm{Al}$ Wejh coast of Tabuk province. There are a few other approaches for the development of wind maps that are accurate and more sensitive to the influence of topography, such as the downscaling process by WAsP calculation used to develop the Global Wind Atlas [41]. However, this influence of topography seems to make little difference in this study due to the exclusion criteria. Different layers of suitable and unsuitable criteria used in this study are shown schematically in Figures A1-A7 in Appendix A.

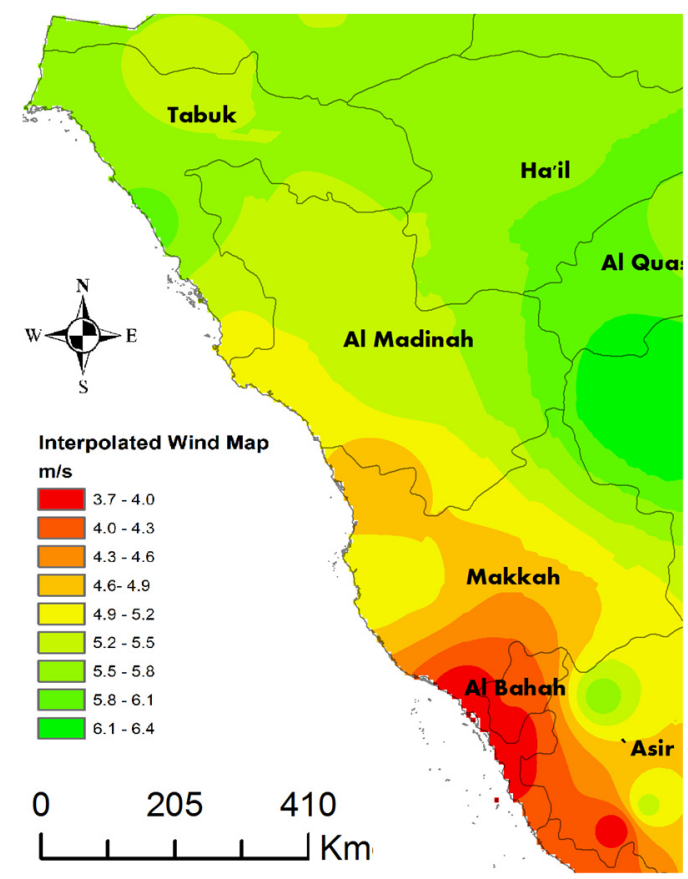

Figure 7. The wind map of the Hijaz region.

\subsection{The Maps with Criteria Restrictions}

The areas with suitable wind resources corresponding to wind speed greater than $5.8 \mathrm{~m} / \mathrm{s}$ are shown on the density map in Figure A1, the remaining area is removed using the "erase" function in 
ArcMap software. All the restrictions to the criteria depicted in Table 3 are applied and the suitability maps for each criterion are shown in Figures A1-A7 in Appendix A. Suitable regions with a continuous area less than $10 \mathrm{~km}^{2}$ are also erased from the final suitability map.

\subsection{The Final Site Suitability Map for the Hijaz Region}

The suitable site selected in this study is near Al Wejh region located in Tabuk province, on the Red Sea coast (Figure 8). It is located nearby an existing highway. There are no suitable sites in the other two provinces, Al-Madinah Al-Monawarah and Makkah Al-Mokarramah.

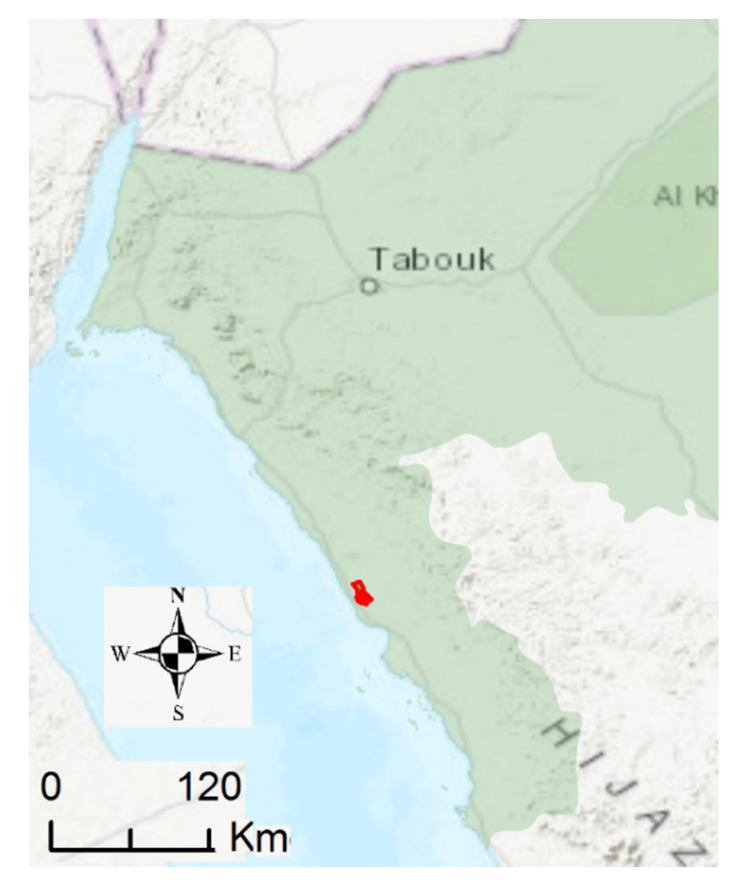

Figure 8. The windfarm site suitability map of the Hijaz area.

\section{Design Optimization of Wind Farm Layout}

\subsection{Selection of Wind Turbine}

A 3 MW rated capacity wind turbine, Vestas V112, was selected for the given region. This wind turbine is suitable for the wind resource of the region and has a very low cut-in wind speed of $2.99 \mathrm{~m} / \mathrm{s}$. The power curve and detailed specifications of the turbine are given in Figure 9 and Table 4, respectively.

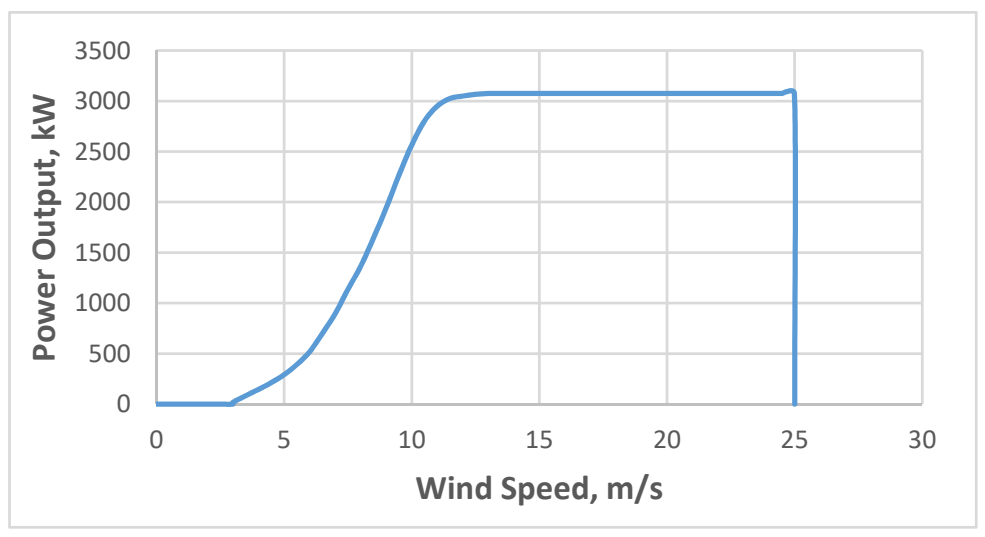

Figure 9. The power curve of the selected wind turbine. 
Table 4. Specifications of the identified wind turbine, Vestas V112-3.0 MW.

\begin{tabular}{cc}
\hline Parameter & Value \\
\hline Class & $\mathrm{Ib}$ \\
Weibull shape, $\mathrm{K}$ & 2 \\
Cut in speed, $\mathrm{m} / \mathrm{s}$ & 2.99 \\
Cut out speed, $\mathrm{m} / \mathrm{s}$ & 25 \\
Diameter, $\mathrm{m}$ & 112 \\
Hub height, $\mathrm{m}$ & 84 \\
Capacity, $\mathrm{kW}$ & 3075 \\
Peak output, $\mathrm{kW}$ & 3075 \\
Power uncertainty, \% & 2.4 \\
Number of blades & 3 \\
Blade width maximum, $\mathrm{m}$ & 4 \\
Blade width at $90 \%$ of radius, $\mathrm{m}$ & 1 \\
Rotor tilt, degrees & 5 \\
\hline
\end{tabular}

\subsection{The Wind Farm Layout Optimization Methodology}

The elevation and the land cover data are downloaded for the identified area of around $5.5 \times 4 \mathrm{~km}^{2}$ in Openwind software. The wind speed and direction data from the four adjacent meteorological stations are downloaded from Windnavigator and the wind map over the selected region is developed. The turbine positions are optimized using the deep-array wake model, DAWM. This model is the most commonly used for onshore wind farm design layout. The optimized layout identified a maximum of 30 wind turbine locations. The layout is then optimized for the cost of energy. This optimization includes the cost of constructing access roads to all the 30 wind turbines from the existing road near the wind farm. The cost of constructing the two substations and the electrical grid connections to all the turbines is also included. The cost of constructing the substation is taken as USD 3,000,000 each. The cost settings for the optimization are shown in Table 5. All the costing data are procured from the Openwind software [42].

Table 5. Cost of energy settings.

\begin{tabular}{cc}
\hline Parameter & Value \\
\hline One-time initial costs, USD & 300,000 \\
Annual costs, USD & $1,000,000$ \\
Project life, years & 25 \\
Discount rate, $\%$ & 8 \\
Tax rate, \% & 0 \\
Debt ratio, \% & 70 \\
Debt interest rate, \% & 7 \\
Debt term, years & 12 \\
\hline
\end{tabular}

An existing road passes by the wind farm layout at a distance of around $1 \mathrm{~km}$. The cost of constructing a $10 \mathrm{~m}$ width road to access each of the 30 wind turbines is also considered. The total cost of constructing this $19.52 \mathrm{~km}$ of the access road is USD 5,897,070 at a rate of USD 300,000 per km. The assumed cost settings for the construction of the access roads and its specifications are shown in Table 6. The shapefiles of terrain slope, waterbodies, and wetlands are imported in the Openwind software and the cost of access road construction incorporates these hindrances. The heavy trucks carrying huge wind turbine parts need at least a $10 \mathrm{~m}$ wide road with a minimum turning radius of $100 \mathrm{~m}$.

The national electricity grid passes by the prospective wind farm layout at a distance of around $5 \mathrm{~km}$. The cost of extending the cabling to reach each of the 30 wind turbines is also considered in the capital cost of the project. The total cost of putting the $115 \mathrm{kV}$ cable lines of $27.58 \mathrm{~km}$ is USD 11,045,187 at a rate of USD 150,000 per $\mathrm{km}$. The assumed cost settings and specifications of the collector system 
are shown in Table 7. As discussed earlier, the shapefiles of the wetlands, new, and existing roads are imported in the software for the detailed cost analysis.

Table 6. Cost settings and specifications of the access roads.

\begin{tabular}{cc}
\hline Parameter & Value \\
\hline Cost per kilometer of using existing road, USD & 100,000 \\
Base cost per kilometer of road, USD & 300,000 \\
Maximum incline for any type of road, \% & 17.5 \\
Additional cost per kilometer of road through steep terrain, USD & 100,000 \\
Steep terrain to be classed as having an incline of at least, \% & 10 \\
Minimum turning radius, m & 100 \\
Cost of crossing a water course, USD & 15,000 \\
Cost of rebuilding a crane, USD & 175,000 \\
Cost of crossing a fence line, USD & 1000 \\
Cost of crossing a railroad, USD & 10,000 \\
Cost of crossing a public road, USD & 10,000 \\
Cost of crossing a pipeline, USD & 10,000 \\
Cost of crossing 1 km of wetland, USD & 100,000 \\
Acceptable fill gradient, degrees & 45 \\
Width of road, m & 10 \\
\hline
\end{tabular}

Table 7. Cost settings and specifications of the collector system.

\begin{tabular}{cc}
\hline Parameter & Value \\
\hline High voltage cable to grid, USD/km & 150,000 \\
High voltage cable to grid, kV & 115 \\
Cost of cable crossing a watercourse, USD & 10,000 \\
Cost of cable crossing a fence line, USD & 1000 \\
Cost of cable crossing a railroad, USD & 10,000 \\
Cost of cable crossing a public road, USD & 10,000 \\
Cost of cable crossing a pipeline, USD & 10,000 \\
Cost of cable crossing 1 km of wetland, USD & 100,000 \\
Cost of feeder bay at the substation, USD & 150,000 \\
Cost-saving of running cable along new roads, $\%$ & 30 \\
\hline
\end{tabular}

The optimized wind farm layout with 30 wind turbine locations, two substations, existing road and electricity grid, and new access roads and collector system grid extension is shown in Figure 10. The final cost of energy, COE, from this optimized wind farm is expected to be USD 65.66 per MWh for the net energy production of $143.1 \mathrm{GWh}$ and gross energy production of $156 \mathrm{GWh}$. The capacity factor obtained for the wind farm is $17.7 \%$ with an array efficiency of $91.7 \%$. The mean free wind speed at the turbine hub height is expected to be $5.26 \mathrm{~m} / \mathrm{s}$. The elliptical separation constraint is used, and the optimized layout has a separation distance of 4 and 15 rotor diameters $(112 \mathrm{~m})$ along the minor and major axis. The details of the energy production and the layout are shown in Table 8. Various other studies elsewhere have reported comparable cost of energy from the optimized wind farm. Luo et al. reported a COE of 45 to 75 USD/MWh for various case studies in the US, China, and Denmark by simultaneously optimizing the wind turbine specifications and the wind farm layout [43]. Stanley et al. reported a COE of 50 to $60 \mathrm{USD} / \mathrm{MWh}$ for optimized wind farm design with wind turbines of multiple hub heights and smaller rotor diameters [44]. Bergvall reported a COE of 100 to 115 USD/MWh for repowered existing offshore wind farms in Denmark by reducing the rated power capacities of wind turbines [45]. 


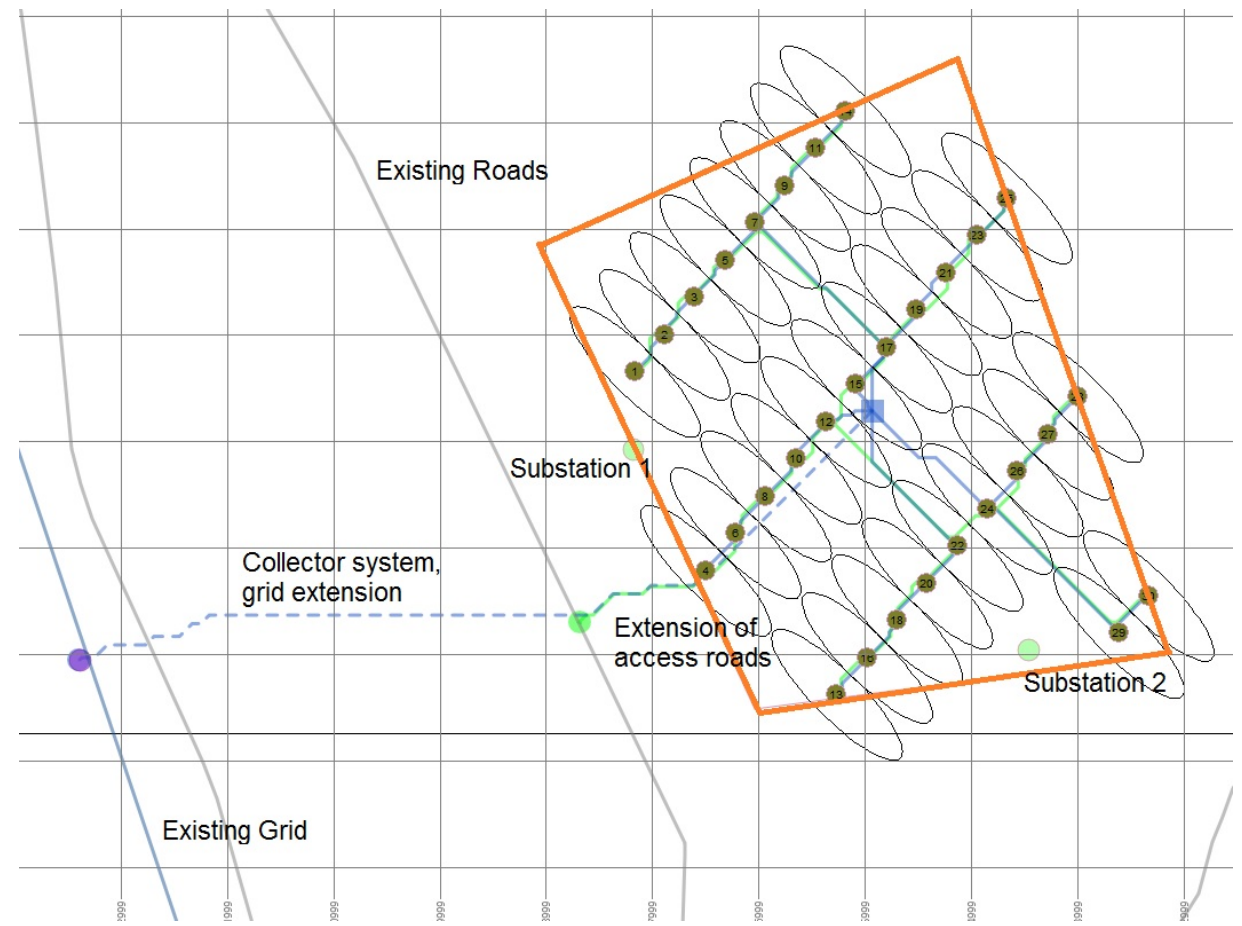

Figure 10. The optimized layout with turbine positions.

Table 8. The data of the energy production.

\begin{tabular}{cc}
\hline Parameter & Value \\
\hline Ideal energy, GWh & 155.95 \\
Theoretical gross energy, GWh & 155.95 \\
Gross energy, GWh & 155.95 \\
Net energy, GWh & 143.1 \\
Capacity factor, $\%$ & 17.7 \\
Topographic efficiency, \% & 100 \\
Array efficiency, $\%$ & 91.74 \\
Air density across site, $\mathrm{kg} / \mathrm{m} 3$ & 1.2 \\
Mean air density at turbines, $\mathrm{kg} / \mathrm{m} 3$ & 1.2 \\
Free wind speed across site, $\mathrm{m} / \mathrm{s}$ & 5.0 \\
Mean free wind speed at turbines, $\mathrm{m} / \mathrm{s}$ & 5.26 \\
Air density at site, $\mathrm{kg} / \mathrm{m} 3$ & 1.225 \\
Separation constraint & Elliptical \\
Minor axis separation distance, RD & 4 \\
Major axis separation distance, RD & 15 \\
Major axis bearing, degrees & 135 \\
Array loss, $\%$ & 8.26 \\
Inclined flow loss, $\%$ & -0.028 \\
\hline
\end{tabular}

\section{Conclusions}

The global energy demand is expected to be doubled by 2050 and, with decreasing fossil fuel reserves, investigating alternative renewable and sustainable resources of energy is a necessity. Since the cost of energy generated from the latest commercial wind turbines is at par with traditional energy from fossil fuels, wind energy has become one of the most emerging renewable sources of energy. In Saudi Arabia, the projected demand for electricity is expected to exceed $120 \mathrm{GW} /$ year by 2032. The first wind farm of 400 MW capacity is being constructed in Dumat al-Jandal, Sakaka, Al Jawf Province, in the north of Saudi Arabia. However, there are no wind farms planned in other parts of the country.

In this study, the energy requirement of the five areas of Saudi Arabia is studied based on their population density. The Hijaz region in the west of Saudi Arabia is considered for wind farm planning 
which has good wind resources and the highest population density compared to other regions. Firstly, a wind map is developed for the Hijaz region based on the long-term historical wind data over a period of 39 years followed by the development of a GIS-based MCDM model for suitable wind farm site selection considering data from various ecological, environmental, and socioeconomic criteria for Hijaz, the western region of Saudi Arabia. A site of $22 \mathrm{~km}^{2}$ is identified near Al Wejh region which satisfies all the criteria restrictions in the model. The criteria restrictions on proximity to roads and electricity grid can be relaxed for large wind farms for long-term benefits and new access roads and grid can be planned. The design optimization of the wind farm layout at the identified site using the deep-array wake model, DAWM, is the next stage after the selection of a suitable wind turbine of $3 \mathrm{MW}$ rated power. There were 30 wind turbine optimum locations in the wind farm site identified in Tabuk province which minimizes the cost and energy losses by wake effect and maximizes the power production. The expected net energy production from the wind farm is $143 \mathrm{GWh}$ with array losses of $8.25 \%$ at a cost of energy of USD 65.66 per MWh and a capacity factor of $17.7 \%$. The cost calculations include the capital and maintenance cost of constructing the access roads and collector system with two substations. The optimized turbine layout has a major axis separation distance of $1680 \mathrm{~m}$ and a minor axis separation of $448 \mathrm{~m}$. The cost of energy is found to be comparable to similar recent studies in the US, China and Denmark. This study is the first of its kind as it combines the GIS-based MCDM modeling involving all the criteria that directly or indirectly affect the wind farm siting and then combines this with the design optimization of the wind farm layout at the identified site. The GIS-based MCDM analysis is performed in ArcMap, the main component of ESRI's ArcGIS suite of geospatial processing programs and the wind resource assessment for the region in and the optimization is performed in Windographer and OpenWind software both developed by AWS true power. This study will help to partially achieve the target of producing $57.5 \mathrm{GW}$ of renewable energy by 2030 by proper site selection in the area with the highest demand and optimum harnessing of wind energy from that region.

Author Contributions: Conceptualization, A.B.M. and S.R.; Methodology, A.B.M.; Data and software curation: S.R.; Investigation, A.B.M. and S.R.; Supervision, S.R. and L.A.; Validation, S.R., A.B.M. and L.A.; Writing-original draft, A.B.M.; Writing-review and editing, A.B.M., S.R. and L.A.; Project administration, S.R. All authors have read and agreed to the published version of the manuscript.

Funding: The research was funded by the Deanship of Scientific Research (DSR) at King Fahd University of Petroleum and Minerals (KFUPM) grant number SB181005.

Conflicts of Interest: The authors declare no conflict of interest.

\section{Appendix A}

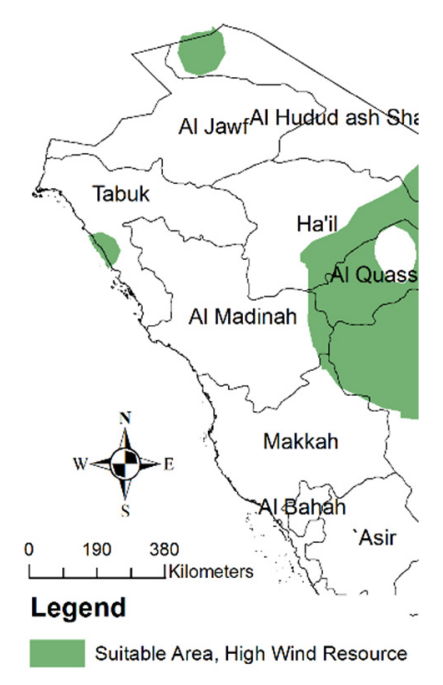

Figure A1. The suitable area based on wind resources. 


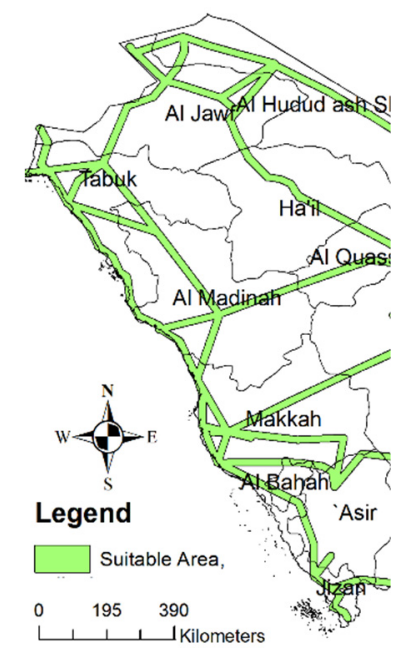

Figure A2. The suitable area based on proximity to the National Electricity Grid.

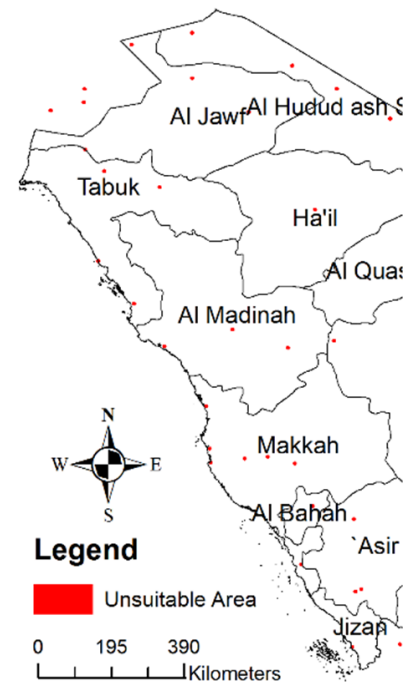

Figure A3. The suitable area based on the safe distance from all aerodromes.

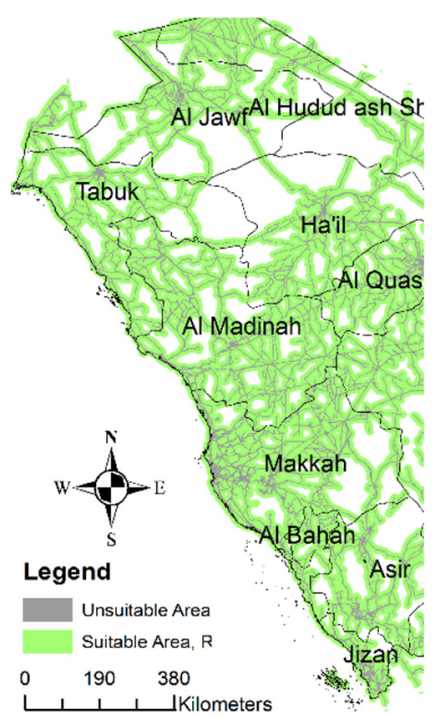

Figure A4. The suitable and unsuitable area based on distance from roads and highways. 


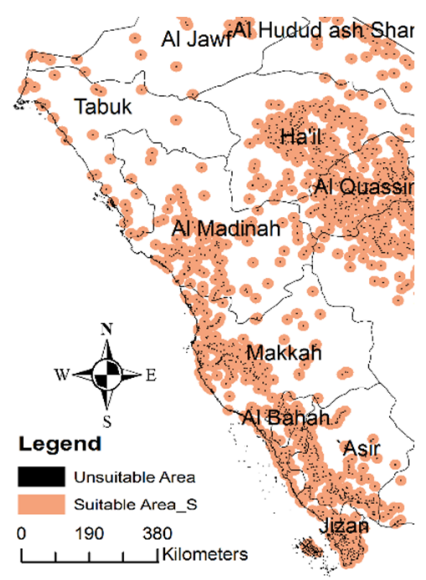

Figure A5. The suitable and unsuitable area based on distance from major settlements.

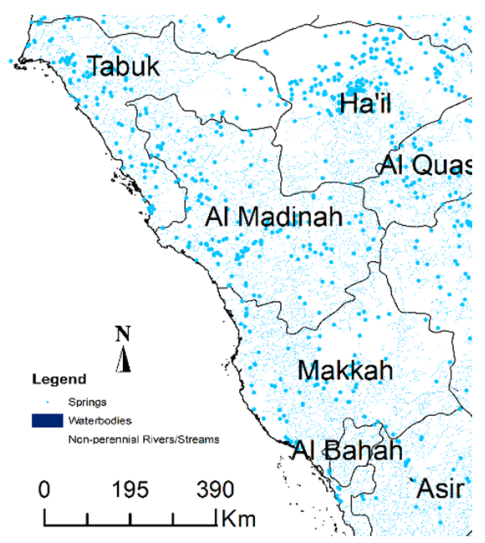

Figure A6. The unsuitable area based on distance from waterbodies, waterways, and springs.

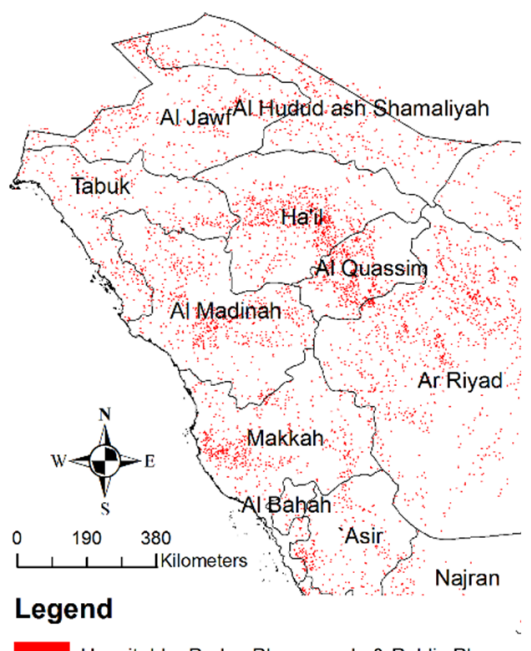

Unsuitable, Parks, Playgrounds \& Public Places

Figure A7. The unsuitable area based on distance from parks, playgrounds, and other public places.

\section{References}

1. U.S. Energy Information Agency. Annual Energy Outlook 2019 with Projections to 2050; U.S. Energy Information Agency: Washington, DC, USA, 2019.

2. Dellosa, J.T. Potential effect and analysis of high residential solar photovoltaic (PV) systems penetration to an electric distribution utility (DU). Int. J. Renew. Energy Dev. 2016, 5, 179-185. [CrossRef] 
3. Noorollahi, Y.; Yousefi, H.; Mohammadi, M. Multi-criteria decision support system for wind farm site selection using GIS. Sustain. Energy Technol. Assess. 2016, 13, 38-50. [CrossRef]

4. GWEC (Global Wind Energy Council). Global Wind Report 2019; GWEC (Global Wind Energy Council): Brussels, Belgium, 2020.

5. Saudi Vision 2030. Council of Economic and Development Affairs. Available online: https://www.vision2030. gov.sa/en (accessed on 1 October 2020).

6. Technology, P. Dumat Al Jandal Wind Farm. Available online: https://www.power-technology.com/projects/ dumat-al-jandal-wind-farm (accessed on 17 February 2020).

7. Baseer, M.A.; Rehman, S.; Meyer, J.P.; Alam, M.M. GIS-based site suitability analysis for wind farm development in Saudi Arabia. Energy 2017, 141, 1166-1176. [CrossRef]

8. Rafique, M.M.; Rehman, S.; Alam, M.M.; Alhems, L.M. Feasibility of a $100 \mathrm{MW}$ installed capacity wind farm for different climatic conditions. Energies 2018, 11, 2147. [CrossRef]

9. Stojčić, M.; Zavadskas, E.K.; Pamučar, D.; Stević, Ž.; Mardani, A. Application of MCDM Methods in Sustainability Engineering: A Literature Review 2008-2018. Symmetry 2019, 11, 350. [CrossRef]

10. Baban, S.M.J.; Parry, T. Developing and applying a GIS-assisted approach to locating wind farms in the UK. Renew. Energy 2001, 24, 59-71. [CrossRef]

11. Hansen, H.S. GIS-based multi-criteria analysis of wind farm development. In Proceedings of the ScanGIS 2005-10th Scandinavian Research Conference on Geographical Information Sciences, Stockholm, Sweden, 13-16 June 2005.

12. Azad, K.; Rasul, M.; Halder, P.; Sutariya, J. Assessment of wind energy prospect by weibull distribution for prospective wind sites in Australia. Energy Procedia 2019, 160, 348-355. [CrossRef]

13. Wang, L.; Tan, A.; Gu, Y. A novel control strategy approach to optimally design a wind farm layout. Renew. Energy 2016, 95, 10-21. [CrossRef]

14. Jensen, N.O. A Note on Wind Generator Interaction; Risø-M-2411; Risø National Laboratory: Roskilde, Danmark, 1983.

15. Katic, I.; Højstrup, J.; Jensen, N.O. A Simple Model for Cluster Efficiency. In Proceedings of the European Wind Energy Association Conference and Exhibition, Rome, Italy, 7-9 October 1986; pp. 407-410.

16. Gualtieri, G. A novel method for wind farm layout optimization based on wind turbine selection. Energy Convers. Manag. 2019, 193, 106-123. [CrossRef]

17. Tifroute, M.; Bouzahir, H. Design optimization of a wind farm layout for maximum wind energy capture: A new constructive approach. Wind Eng. 2017, 42, 155-163. [CrossRef]

18. Charhouni, N.; Sallaou, M.; Mansouri, K. Realistic wind farm design layout optimization with different wind turbines types. Int. J. Energy Environ. Eng. 2019, 10, 307-318. [CrossRef]

19. Frandsen, S.T. Turbulence and Turbulence-Generated Structural Loading in Wind Turbine Clusters. Ph.D. Thesis, Technical University of Denmark, Kgs Lyngby, Denmark, 2007.

20. Liu, F.; Ju, X.; Wang, N.; Wang, L.; Lee, W.J. Wind farm macro-siting optimization with insightful bi-criteria identification and relocation mechanism in genetic algorithm. Energy Convers. Manag. 2020, 217, 112964. [CrossRef]

21. Ju, X.; Liu, F. Wind farm layout optimization using self-informed genetic algorithm with information guided exploitation. Appl. Energy 2019, 248, 429-445. [CrossRef]

22. Tao, S.; Xu, Q.; Feijóo, A.; Zheng, G.; Zhou, J. Wind farm layout optimization with a three-dimensional Gaussian wake model. Renew. Energy 2020, 159, 553-569. [CrossRef]

23. Sørensen, T.; Nielsen, P.; Thøgersen, M.L. Recalibrating wind turbine wake model parameters-Validating the wake model performance for Large offshore Wind Farms. In Proceedings of the European Wind Energy Conference and Exhibition 2006, EWEC 2006, Athens, Greece, 27 February-2 March 2006.

24. Barthelmie, R.J.; Hansen, K.; Frandsen, S.T.; Rathmann, O.; Schepers, J.G.; Schlez, W.; Phillips, J.; Rados, K.; Zervos, A.; Politis, E.S.; et al. Modelling and measuring flow and wind turbine wakes in large wind farms offshore. Wind Energy 2009, 12, 431-442. [CrossRef]

25. Baseer, M.A.; Meyer, J.P.; Rehman, S.; Alam, M.M. Wind power characteristics of seven data collection sites in Jubail, Saudi Arabia using Weibull parameters. Renew. Energy 2017, 102, 35-49. [CrossRef]

26. Hulio, Z.H.; Jiang, W.; Rehman, S. Techno-Economic assessment of wind power potential of Hawke's Bay using Weibull parameter: A review. Energy Strateg. Rev. 2019, 26, 100375. [CrossRef] 
27. Peros, B.; Boko, I.; Divic, V. Wind shear characteristics of local winds. In Proceedings of the 7th Asia-Pacific Conference on Wind Engineering, APCWE-VII, Taipei, Taiwan, 8-12 November 2009.

28. Rehman, S.; Baseer, M.A.; Alhems, L.M. GIS-based multi-criteria wind farm site selection methodology. FME Trans. 2020, 48, 855-867. [CrossRef]

29. Islam, M.S.; Mohandes, M.; Rehman, S. Vertical extrapolation of wind speed using artificial neural network hybrid system. Neural Comput. Appl. 2017, 28, 2351-2361. [CrossRef]

30. Annual Report 2019; Annual Report; Saudi Electricity Company: Riyadh, Saudi Arabia, 2019.

31. Aydin, N.Y.; Kentel, E.; Duzgun, S. GIS-based environmental assessment of wind energy systems for spatial planning: A case study from Western Turkey. Renew. Sustain. Energy Rev. 2010, 14, 364-373. [CrossRef]

32. Latinopoulos, D.; Kechagia, K. A GIS-based multi-criteria evaluation for wind farm site selection. A regional scale application in Greece. Renew. Energy 2015, 78, 550-560. [CrossRef]

33. Siyal, S.H.; Mörtberg, U.; Mentis, D.; Welsch, M.; Babelon, I.; Howells, M. Wind energy assessment considering geographic and environmental restrictions in Sweden: A GIS-based approach. Energy 2015, 83, 447-461. [CrossRef]

34. Van Haaren, R.; Fthenakis, V. GIS-based wind farm site selection using spatial multi-criteria analysis (SMCA): Evaluating the case for New York State. Renew. Sustain. Energy Rev. 2011, 15, 3332-3340. [CrossRef]

35. Sliz-Szkliniarz, B.; Vogt, J. GIS-based approach for the evaluation of wind energy potential: A case study for the Kujawsko-Pomorskie Voivodeship. Renew. Sustain. Energy Rev. 2011, 15, 1696-1707. [CrossRef]

36. EarthWorks, Stanford Libraries; ESRI: Redlands, CA, USA, 2020.

37. Babbington, J. Birds of Saudi Arabia. Available online: https://www.birdsofsaudiarabia.com/p/birdinglocations.html (accessed on 10 February 2020).

38. Shobrak, M. Bird flyways and stopover conservation sites in the arabian peninsula. Zool. Middle East 2011, 54, 27-30. [CrossRef]

39. Tegou, L.I.; Polatidis, H.; Haralambopoulos, D.A. Environmental management framework for wind farm siting: Methodology and case study. J. Environ. Manag. 2010, 91, 2134-2147. [CrossRef] [PubMed]

40. Rahman, F.; Rehman, S.; Abdul-Majeed, M.A. Overview of energy storage systems for storing electricity from renewable energy sources in Saudi Arabia. Renew. Sustain. Energy Rev. 2012, 16, 274-283. [CrossRef]

41. The Global Wind Atlas; Technical University of Denmark, DTU: Kgs Lyngby, Denmark, 2019; Available online: https://globalwindatlas.info/ (accessed on 31 October 2020).

42. Openwind. Most Advanced Software for Creating and Optimizing Turbine Layouts. Available online: https://www.ul.com/resources/apps/openwind (accessed on 13 November 2020).

43. Luo, L.; Zhang, X.; Song, D.; Tang, W.; Li, L.; Tian, X. Minimizing the energy cost of offshorewind farms by simultaneously optimizing wind turbines and their layout. Appl. Sci. 2019, 9, 835. [CrossRef]

44. Stanley, A.P.J.; Ning, A.; Dykes, K. Optimization of turbine design in wind farms with multiple hub heights, using exact analytic gradients and structural constraints. Wind Energy 2019, 22, 605-619. [CrossRef]

45. Bergvall, D. Cost Comparison of Repowering Alternatives for Offshore Wind Farms; Uppsala University: Uppsala, Sweden, 2019.

Publisher's Note: MDPI stays neutral with regard to jurisdictional claims in published maps and institutional affiliations.

(C) 2020 by the authors. Licensee MDPI, Basel, Switzerland. This article is an open access article distributed under the terms and conditions of the Creative Commons Attribution (CC BY) license (http://creativecommons.org/licenses/by/4.0/). 